\title{
Identification and Quantification of Fructoborate Ester Complex Using Liquid Chromatography Coupled with Q Exactive Orbitrap Mass Spectrometry
}

\author{
Xiaoyan Xia ${ }^{1}$, James S. Chang ${ }^{2}$, John M. Hunter ${ }^{1}$ \& Boris V. Nemzer ${ }^{1,3}$ \\ ${ }^{1}$ VDF FutureCeuticals, Inc., Momence, IL, USA \\ ${ }^{2}$ Thermo Scientific, San Jose, CA, USA \\ ${ }^{3}$ Department of Food Science and Human Nutrition, University Illinois at Urbana Champaign, Urbana, IL, USA \\ Correspondence: Boris Nemzer. FutureCeuticals, Inc. 2692 N. State Rt. 1-17, Momence, IL, 60954, USA. Tel: \\ 1-812-507-1427. E-mail: bnemzer@futureceuticals.com
}

Received: March 22, $2017 \quad$ Accepted: April 18, $2017 \quad$ Online Published: April 27, 2017

doi:10.5539/jfr.v6n3p85 URL: https://doi.org/10.5539/jfr.v6n3p85

\begin{abstract}
The identification of fructoborate complex in food matrices using liquid chromatography coupled with quadrupole Orbitrap mass spectrometry was investigated in this study. The LC/MS method was established by optimization of mobile phases and direct infusion of FruiteX-B ${ }^{\circledR}$ brand calcium fructoborate $(\mathrm{CaFB})$ solution to Q Exactive Orbitrap mass spectrometer to obtain MS operation parameters. The precursor ion $\mathrm{m} / \mathrm{z} 367.10522$ was dissociated further for conformation analysis of fructoborate complex. The method was applied to identify and quantify fructoborate in freeze dried apricot fruit and raisins. It was found that fructose- ${ }^{11} \mathrm{~B}$-fructose di-ester complex was present in these fruits. The results were further verified by multinuclear solid and liquid states NMR spectroscopy analysis.
\end{abstract}

Keywords: sugar-borate ester, fructoborate, fructose, liquid chromatography, mass spectrometer

\section{Introduction}

Calcium fructoborate is a sugar-borate ester complex with a boron molecule linked to one or two fructose molecules to form fructoborate mono- or di-ester, respectively. This complex is industrially formed by a proprietary reaction of boric acid with fructose and calcium carbonate. Natural and identical fructoborate esters are found in some fruits and vegetables (Matsunaga \& Nagata, 1995; Brown \& Shelp, 1997; Hu, Penn, Lebrilla \& Brown, 1997). Numerous studies (Brown \& Hu, 1994; Kobayashi, Matoh \& Azuma, 1996; Brown et al., 2002) have shown that borates are critical in plant growth processes such as normal growth of cell wall, membrane function, and lignin biosynthesis, and are also important to human health ( I. Scorei \& R. Scorei, 2013; Dinca \& Scorei, 2013; Scorei, Cimpoiasu \& Iordachescu, 2005; Milijkovic et al., 2009): calcium fructoborate is a potential anti-inflammatory nutrient and its antioxidant activity can protect cells from oxidant-induced injury; both calcium fructoborate and boric acid can inhibit the growth of breast cancer cells. Recent studies (Pietrzkowski et al., 2014; Reyes-Iaquierfo et al., 2012; R. Scorei, Mitrut, Petrisor \& Scorei, 2011) suggested that borates may help regulate hormones and vitamin D in a manner that improves bone and joint health. A short-term intake of calcium fructoborate provided significant benefits to people experiencing conditions associated with knee osteoarthritis (Reyes-Iaquierfo, Nemzer \& Gonzalez, 2012; D. Miljkovic, N. Miljkovic \& McCarty, 2004). Studies (Mogosanu et al., 2016; Scorei, Ciofrangeanu \& Ion, 2010; Scorei \& Rotaru, 2011; Scorei, 2011; Militaru et al., 2013) demonstrated the ability of calcium fructoborate to significantly modulate molecular markers associated with inflammatory mechanisms on the elevated serum levels of C-reactive protein, suggesting possible benefit for cardiovascular conditions. Scorei and some researchers (Scorei \& Popa, 2010; Scorei et al., 2007) found negative correlation between borate intake and the incidence of other human health issues.

Since boron has been shown to be essential for plant growth, different methods have been developed to characterize sugar-borate complexes in plants (Hu et al., 1997; Wagner et al., 2008). Matoh et al. (1993) purified boron-polysaccharide complex from radish roots, further hydrolyzed the complex of polysaccharide, and characterized the state of boron in complex by NMR. Hu et al. (1997) used matrix-assisted laser 
desorption-Fourier transform mass spectrometry to analyze soluble boron complexes, with verification by high-performance liquid chromatography and gas chromatography-mass spectrometry. To further understand the primary functions of sugar-borate complexes in plants and human health, a more effective screening method is required to identify this complex compound in various sample matrices, especially at low concentration levels.

In this study, we established an analytical method to identify fructoborate using ultra high performance liquid chromatography coupled with high resolution quadrupole Orbitrap mass spectrometry. The method was optimized by using Fruitex- $\mathrm{B}^{\circledR}$ brand calcium fructoborate as a standard and was thereafter applied in order to identify fructoborate complex naturally presented in different fruit powders.

\section{Material and Method}

\subsection{Material}

Suprapur ${ }^{\circledR}$ formic acid, Omnisolv ${ }^{\circledR}$ LC-MS grade of methanol and acetonitrile and 99\% OmniTrace ${ }^{\circledR}$ glacial acetic acid were purchased from EMD Millipore Corporation (Billerica, MA, USA); Optima ${ }^{\circledR}$ LC/MS grade of ammonium acetate and ammonium formate was obtained from Fisher Scientific (Fair Lawn, NJ, USA); BDH LC-MS grade of water was ordered from VWR international (Radnor, PA, USA). Fruitex-B ${ }^{\circledR}$ brand calcium fructoborate is exclusively manufactured under US patent 5,962,049 (Miljkovic, 1999) and obtained from VDF FutureCeuticals, Inc. (Momence, IL, USA). VDF FutureCeuticals also provided samples of freeze dried apricot and raisins.

\subsection{Instrumentation and Method}

The UHPLC/Q Exactive Orbitrap system consists of Ultimate 3000 UHPLC coupled with a Q Exactive mass spectrometer (Thermo Fisher Scientific, Bremen, Germany). The system was controlled by Xcalibur 4.0 software (Thermo Fisher Scientific, San Jose, USA)

The analytical column used was a Thermo Acclaim ${ }^{\mathrm{TM}}$ HILIC-10 $150 \mathrm{~mm}$ x $2.1 \mathrm{~mm}$ i.d. and particle size was 3 $\mu \mathrm{m}$. Mobile phase consisted of $90 \%$ acetonitrile $10 \% 0.1 \mathrm{M}$ ammonium acetate was running isocratic. The total running time was 12 mins. The sample injection volume was $2 \mu \mathrm{L}$.

A heated electrospray ionization (HESI) source was used in the Q Exactive mass spectrometer. The optimized operation parameters were set: capillary temperature $256{ }^{\circ} \mathrm{C}$; spray voltage $3.0 \mathrm{kv}$, sheath gas flow rate 48 arbitrary unit, auxiliary gas flow rate 11 arbitrary unit, and auxiliary gas heater temperature $413{ }^{\circ} \mathrm{C}$ respectively. All of the data were acquired using full MS scan mode and DIA (data independent acquisition) mode in negative polarity mode. With the full-scan, the mass range was from m/z 100 to m/z 900. The mass resolution of the mass spectrometer was set at 70000 FWHM (Full width at half maximum, m/z 200) and AGC (Automatic gain control) target at 3e6. CaFB solution was run in full MS scan first to obtain the precursor ion of fructoborate $\mathrm{m} / \mathrm{z}$ 367.10522. In the DIA experiment, the mass spectrometer performed data independent acquisition, and covered the scan range by targeted HCD (higher energy collisional dissociation) events with isolation windows defined in the inclusion list for confirmation analysis. The targeted precursor ion $\mathrm{m} / \mathrm{z} 367.10522$ was included in the inclusion list. The precursor ion was fragmented with normalized collision energy to yield the product ions. The mass resolution of the mass spectrometer was set at 35000 FWHM and NCE (normalized fragmentation energy) $30 \%$. AGC target was set at $1 \mathrm{e} 6$ and isolation window at $3 \mathrm{~m} / \mathrm{z}$. The full MS scan and data independent acquisition were run sequentially at the same time.

ESI Mass spectrometer ion source parameters were first obtained by flow injection analysis, and then optimized based on the mobile phases and flow rate used. Typically, the standard solution was prepared in water by using CaFB powder at final concentration of $5 \mu \mathrm{g} / \mathrm{mL}$, which yielded intense deprotonated molecular anion $[\mathrm{M}-\mathrm{H}]^{-}$by negative ion electrospray ionization. Sensitivity was checked by comparing the intensity of fructoborate running in both positive and negative ionization modes. Full MS scan was run first to screen the CaFB standard solution to obtain the precursor ion of fructoborate with accurate mass measurement $\mathrm{m} / \mathrm{z} 367.10522$. This precursor ion was used in the inclusion list to conduct data independent acquisition and the fragment ions were used to confirm the presence of fructoborate at low concentrations.

\subsection{Method Validation}

For linearity, six different concentrations of CaFB solutions were prepared containing 9.95, 19.9, 49.75, 79.6, 99.5 and $199 \mu \mathrm{g} / \mathrm{mL} \mathrm{CaFB}$ and run on LC/MS to get calibration curve. Each standard solution was injected in duplicate and linearity was evaluated by regression analysis. System precision was evaluated by analyzing the standard solution for seven times on the same day. Accuracy was assessed by determination of the recovery from three food matrix samples spiking with a known amount of CaFB standard. 


\subsection{Sample Preparation Method}

Freeze dried apricot powder and freeze dried raisin powder were prepared for fructoborate analysis. About $0.1 \mathrm{~g}$ of each sample was accurately weighed and quantitatively transferred to a $50 \mathrm{~mL}$ ultraclean centrifuge tube. 10 $\mathrm{mL}$ of LC/MS grade of water was added to the samples. The centrifuge tube was capped, vortexed briefly, shaken for $20 \mathrm{mins}$, and then centrifuged at $6000 \mathrm{rpm} 20^{\circ} \mathrm{C}$ for $10 \mathrm{mins}$. The extracts were filtered into the auto sampler vials using $0.2 \mu \mathrm{m}$ PTFE membrane filter for LC/MS analysis.

\section{Results and Discussion}

\subsection{Method Optimization}

To achieve the best separation and retention for fructoborate, different solvents were tested as mobile phases with Thermo Accucore aQ column (Table1), however, the retention time was less than one minute. Then Thermo Acclaim $^{\mathrm{TM}}$ HILIC-10 column was tested by using $90 \%$ acetonitrile/10\% $0.1 \mathrm{M}$ ammonium acetate as mobile phase. It was found that a good retention was achieved using Thermo Acclaim ${ }^{\mathrm{TM}}$ HILIC-10 column and $90 \%$ acetonitrile/10\% 0.1M ammonium acetate was used as mobile phase to analyze different samples.

Table1. Different mobile phases tested with different columns

\begin{tabular}{l|l}
\hline \multicolumn{1}{c|}{ Column } & \multicolumn{1}{c}{ Mobile phase } \\
\hline Thermo Accucore aQ & water:acetonitrile (w/o 0.1\% formic acid) \\
& water:methanol (w/o $0.1 \%$ formic acid) \\
& water:acetonitrile $(0.1 \%$ formic acid, ammonium formate) \\
& water:methanol (0.1\% formic acid, ammonium formate) \\
\hline Thermo Acclaim ${ }^{\mathrm{TM}}$ HILIC-10 & water:acetonitrile (w/o $0.1 \%$ formic acid) \\
& $90 \%$ acetonitrile/10\% $0.1 \mathrm{M}$ ammonium acetate \\
\hline
\end{tabular}

To determine linearity, a calibration graph was acquired by plotting CaFB concentration again peak area. Linearity was good in the concentration range of $9.95-199 \mu \mathrm{g} / \mathrm{mL}$ CaFB. Calibration curves exhibited excellent polynomial regression over the entire concentration range with regression coefficients in the range of $0.993-0.999$. The limit of instrument detection and quantification were $0.2 \mu \mathrm{g} / \mathrm{mL}$ and $0.5 \mu \mathrm{g} / \mathrm{mL}$ respectively using Thermo Accucore aQ column. System precision was $101 \%$ with RSD\% of 5\%. The accuracy of the method was evaluated by spiking a known amount of CaFB into the food matrix and the average of recovery is $83.7 \%$.

\subsection{Identification of Fructoborate}

FruiteX $B \circledR$ brand calcium fructoborate primarily contains di-ester complex (possible structures shown in Figure 1) which dissociates in water into Fructose-B-Fructose complex. The optimized LC and mass spectrometric parameters were used to analyze CaFB solution with full MS scan and DIA data independent acquisition. Fructoborate was eluted from analytical column at $5.38 \mathrm{~min}$. Figure 2 shows the corresponding mass spectrum. In negative mode, fructoborate yields abundant $[\mathrm{M}-\mathrm{H}]^{-}$ion by ESI (electrospray ionization). Following DIA under high dissociation collision energy, the $[\mathrm{M}-\mathrm{H}]^{-}$ion yields a series of fragment ions that reflect inductive cleavage, hydrogen transfer, and neutral losses. The mass spectrum analysis showed that the precursor ion of Fructose- ${ }^{11}$ B-Fructose complex is $\mathrm{m} / \mathrm{z} 367.10522$ with one negative charge. Compared to the theoretical value of Fructose- ${ }^{11} \mathrm{~B}$-Fructose in negative mode $\mathrm{m} / \mathrm{z} 367.10479$, the mass accuracy of measured precursor ion was $1.17 \mathrm{ppm}$ which is far less than $5 \mathrm{ppm}$. The measured relative isotopic abundance of $\left[{ }^{10} \mathrm{~B}\right]:\left[{ }^{11} \mathrm{~B}\right](16.78 \%: 100 \%)$ and $[12 \mathrm{C}]:[13 \mathrm{C}](100 \%: 1.2 \%)$ were precisely close to theoretical values. The major fragment ions of $\mathrm{m} / \mathrm{z}$ 367.10522, as shown in Figure 2, include $\mathrm{m} / \mathrm{z} 277.07321, \mathrm{~m} / \mathrm{z}$ 205.05154, m/z 187.04088 and m/z 157.03021 with elemental compositions C9H14O9B, C6H10O7B, C6H8O6B and C5H6O5B respectively. From these fragment ions, it can be proposed that the major pathway for the formation of ion $\mathrm{m} / \mathrm{z} 277.07321$ (C9H14O9B) may arise from the decomposition of the precursor ion $\mathrm{m} / \mathrm{z} 367.10522(\mathrm{C} 12 \mathrm{H} 20 \mathrm{O} 12 \mathrm{~B})$. The $\mathrm{m} / \mathrm{z} 205.05154$ (C6H10O7B) ion may be fructose-borate, a loss of one fructose from the fructoborate di-ester complex. The elimination of $\mathrm{H}_{2} \mathrm{O}$ may be involved in the transition from $\mathrm{m} / \mathrm{z} 205.05154$ to $\mathrm{m} / \mathrm{z} 187.04088$ (C6H8O6B), and the $\mathrm{m} / \mathrm{z}$ 157.03021 (C5H6O5B) ion may arise from a neutral loss of $\mathrm{CH}_{2} \mathrm{O}$ from $\mathrm{m} / \mathrm{z} 187.04088$. 


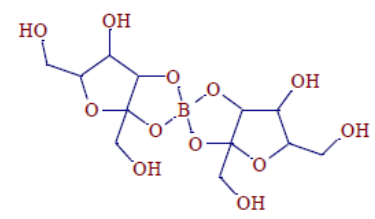

Bis $(\beta$-D-FF) (S) 2, 3: 2', 3'-borate
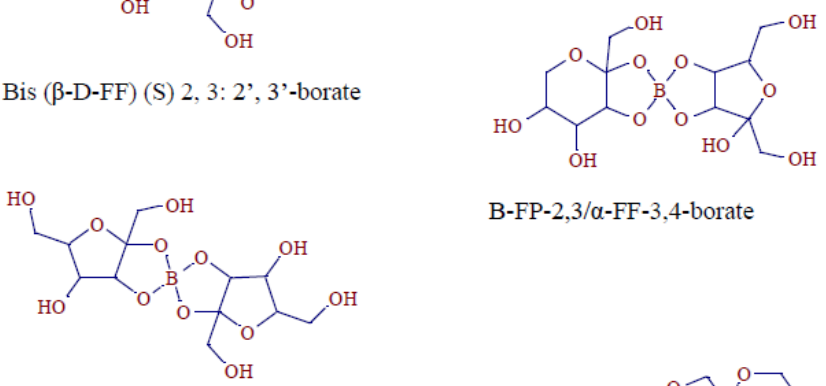

B-FP-2,3/ $\alpha$-FF-3,4-borate

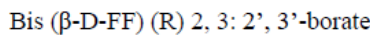
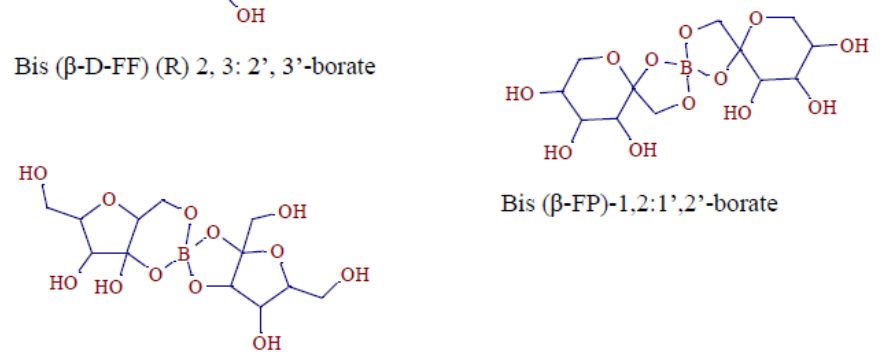

Bis ( $\beta$-FP)-1,2:1',2'-borate

$\alpha$-FF-1,2/ $\beta$-FF-2,3-borate

Figure 1. Possible structures of fructoborate (Fructose- ${ }^{11} \mathrm{~B}$-Fructose) complex, with $\alpha$-FF-B-complex as the dominant form in $\mathrm{CaFB}$

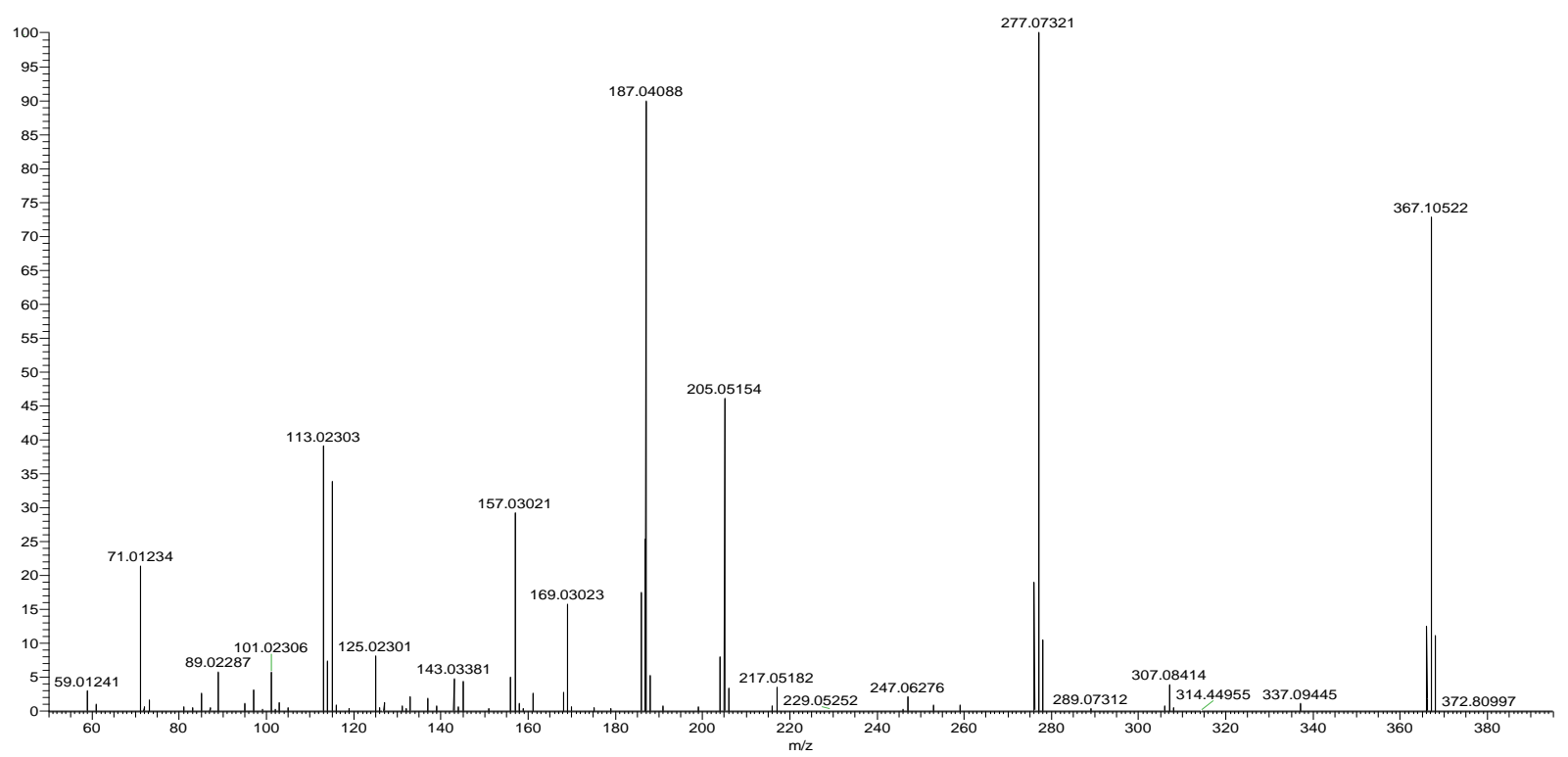

Figure 2. MS/MS mass spectrum of fructoborate with precursor ion m/z 367.10522 at 30\% NCE

As mentioned above, calcium fructoborate complex is formed by a reaction of boric acid with fructose and calcium carbonate. Study (Makkee, Kieboom \& Bekkum, 1985) shows the final product of boric acid and fructose reaction depends on the reaction conditions such as $\mathrm{pH}$ and relative concentration ratio of boric acid and fructose. There are three types of boron-containing molecules observed in the boric acid and D-fructose reaction: boric acid, di-ester complex, and monoester complex with different overall borate ester stabilities (Hu et al., 1997; Makkee et al, 1985). At high $\mathrm{pH}$ value and high D-fructose/borate ratio, the di-ester complex is the dominant product, especially $\alpha$-FF-B-complex ( $\alpha$-fructofuranose-boron-complex). To screen free boric acid and mono-ester complex in $\mathrm{CaFB}$ solution, the same analytical strategies as use when analyzing fructoborate were 
applied and the precursor ions of free boric acid and mono-ester complex were included in the inclusion list. However, no major peaks were found due to low concentrations of these target compounds. This result is consistent with the previous NMR study (Edwards, Hunter \& Nemzer, 2014) and demonstrates further that fructoborate is the dominant product in calcium fructoborate.

\subsection{Identification and Quantification of Fructoborate in Apricot and Raisin}

$\mathrm{CaFB}$, freeze dried apricot, and raisin samples were analyzed by LC/MS. The fructoborate peaks were eluted at $5.38 \mathrm{~min}, 5.40$ and $5.38 \mathrm{~min}$ respectively. The MS/MS mass spectrums of target compound in apricot extract, raisin extract, and fructoborate in $\mathrm{CaFB}$ are shown in Figure 3 and Figure 4. The precursor ion of target compound in apricot powder extract is $\mathrm{m} / \mathrm{z}$ 367.10556, which yields $2.097 \mathrm{ppm}$ mass accuracy compared with theoretical value of fructoborate. The precursor ion of target compound in raisin extract is $\mathrm{m} / \mathrm{z} 367.10532$, which yields $1.444 \mathrm{ppm}$ mass accuracy. The precursor ion and the product ions $(\mathrm{m} / \mathrm{z} 277.07364, \mathrm{~m} / \mathrm{z} 205.05188, \mathrm{~m} / \mathrm{z}$ 187.04117 and m/z 157.03046 for apricot extract; m/z 277.07346, m/z 205.05174, m/z 187.04106 and m/z 157.03035 for raisin extract) of the target compound in both apricot and raisin extract are correspondingly consistent with those of fructoborate. In addition, boron isotope ratios (Table 2) in FrxB solution also unambiguously demonstrate the presence of saccharide-borate complex in these samples. This result is consistent with other studies (Hu et al., 1997; Bieleski \& Redgwell, 1980) that fructoborate is the major borate-saccharide complex in celery and peach nectar.

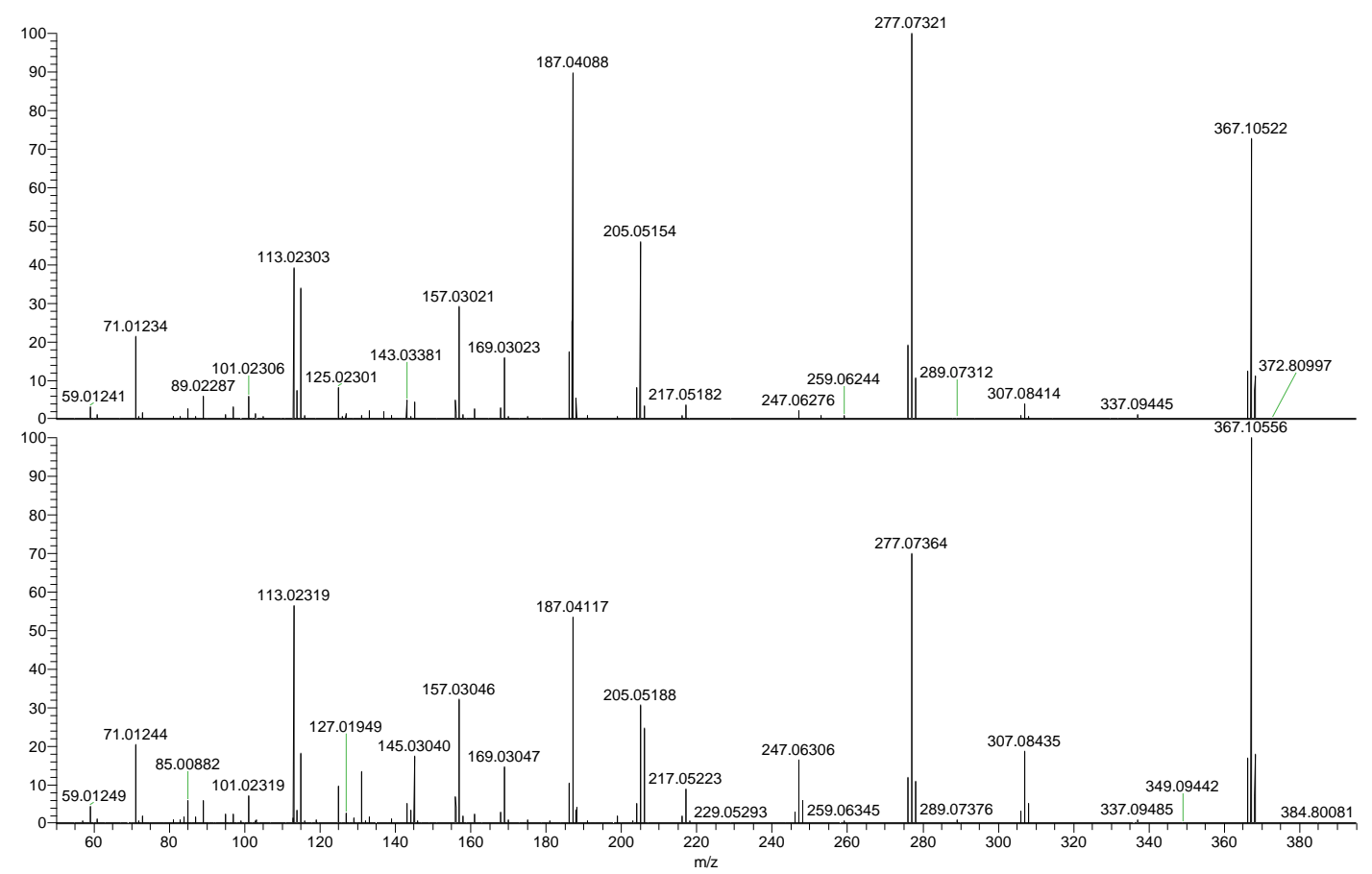

Figure 3. MS/MS spectrum of fructoborate in calcium fructoborate solution (upper) and apricot extract at 30\% NCE (bottom) 


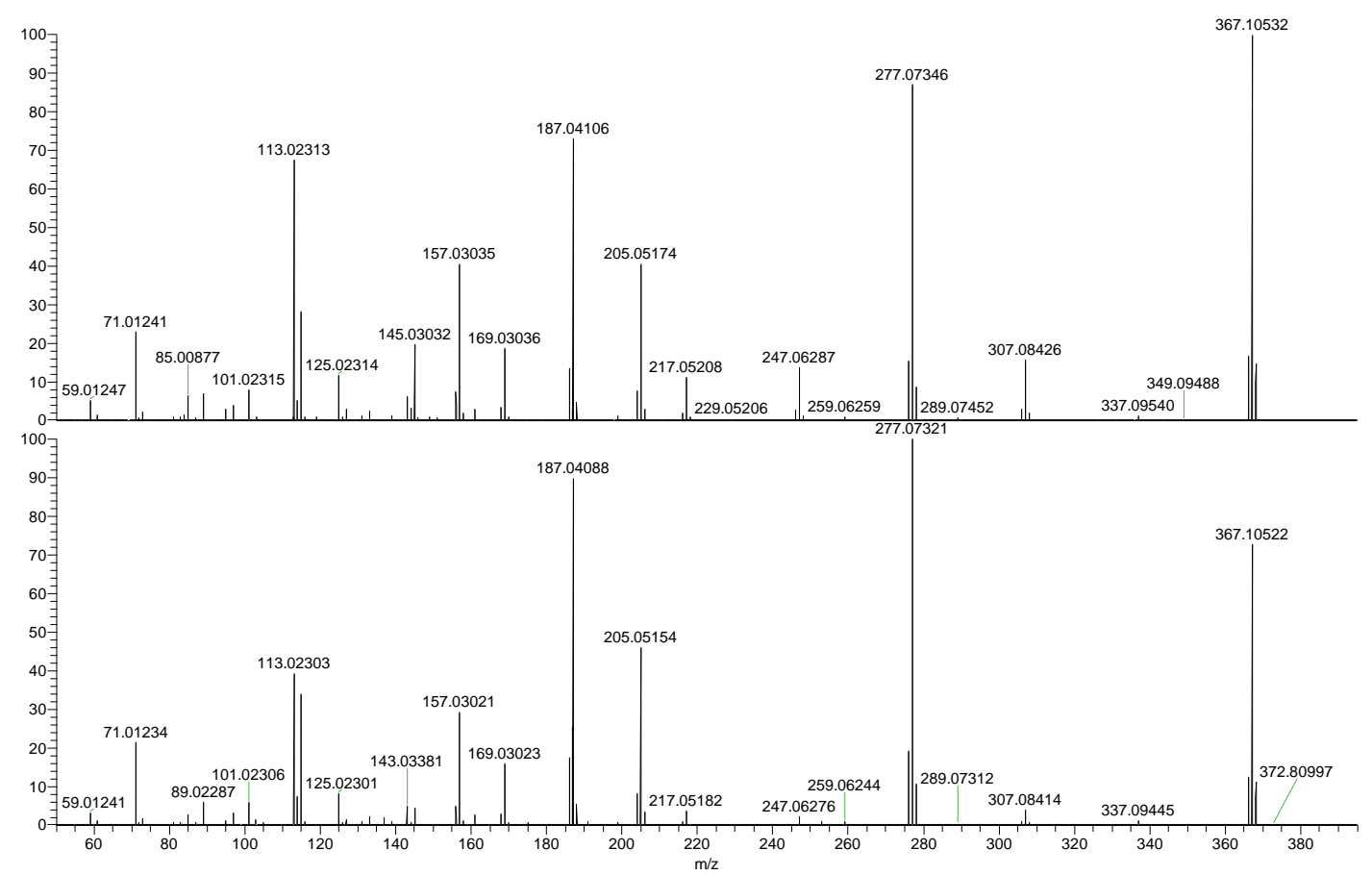

Figure 4. MS/MS spectrum of fructoborate in raisin extract (upper) and calcium fructoborate solution at 30\% NCE (bottom)

Table 2. Relative isotope abundance of ${ }^{10} \mathrm{~B}:{ }^{11} \mathrm{~B}$ in $\mathrm{CaFB}$ solution, apricot extract and raisin extract

\begin{tabular}{cccc}
\hline Ions $\left({ }^{11} \mathrm{~B}\right)$ & FruiteX B® $(\mathrm{CaFB})$ & Apricot extract & Raisin extract \\
\hline $\mathrm{m} / \mathrm{z} 367.10$ & $16.78: 100$ & $16.92: 100$ & $16.8: 100$ \\
$\mathrm{~m} / \mathrm{z} 277.07$ & $18.9: 100$ & $17.16: 100$ & $17.78: 100$ \\
$\mathrm{~m} / \mathrm{z} 205.05$ & $18.1: 100$ & $17.46: 100$ & $17.05: 100$ \\
$\mathrm{~m} / \mathrm{z} 187.04$ & $19.14: 100$ & $19.94: 100$ & $18.4: 100$ \\
$\mathrm{~m} / \mathrm{z} 157.03$ & $17.52: 100$ & $21.96: 100$ & $18.3: 100$ \\
\hline
\end{tabular}

To quantify fructoborate in freeze dried apricot and raisin, six different concentrations of CaFB solutions were prepared containing 9.95, 19.9, 49.75, 79.6, 99.5 and $199 \mu \mathrm{g} / \mathrm{mL} \mathrm{CaFB}$ and run on LC/MS to get calibration curve. Calibration curves exhibited excellent polynomial regression over the entire concentration range with regression coefficients in the range of 0.993-0.999. The calibration curve was then used to be interpolated to quantitate apricot and raisin samples. The resultant determinations are expressed as CaFB equivalents. Both freeze dried apricot and raisin were run triplicate and the concentrations were $16.2 \pm 0.6 \mathrm{mg}(\mathrm{CaFB}) / \mathrm{g}$ sample for apricot and 79.3 $\pm 8.8 \mathrm{mg}(\mathrm{CaFB}) / \mathrm{g}$ sample for raisin respectively. However, matrix effects have become a major concern in quantification analysis. Both ionization suppression and ionization enhancement were detected during method development. Based on the calibration solutions prepared in water, the quantified fructoborate concentrations in apricot and raisin listed above were higher than expected concentrations due to matrix effects. To reduce the matrix effects, the standard addition method was used to quantify fructoborate in those samples further to correct data. The concentration values of fructobroate obtained from using the standard addition method were 10 40 times lower than uncorrected values. The matrix effect is still under investigation for different sample matrices.

\section{Conclusion}

A novel analytical method for fructoborate analysis was developed by using ultra high performance liquid chromatography coupled with high resolution quadrupole Orbitrap mass spectrometry. The basic chromatographic conditions were designed, and selected after testing different conditions that affect HPLC analysis. Thermo Acclaim ${ }^{\mathrm{TM}}$ HILIC-10 column was used because of its better retention for fructoborate. $90 \%$ acetonitrile/10\% 0.1M ammonium acetate were used as mobile phase to get better peak shape and good resolution. The screening of fructoborate in freeze dried apricot and raisin samples demonstrates the potential of 
this analytical method to identify and quantify fructoborate at low concentrations in fruits, vegetables, nuts, and seeds samples. In the future, the method could be optimized further to quantify fructoborate in different plant samples as well as biological samples.

\section{References}

Bieleski, R. L., \& Redgwell, R. J. (1980). Sorbitol metabolism in nectaries from flowers of Rosaceae. Aust J Plant Physiol, 7, 15-25. https://doi.org/10.1071/PP9800015

Brown, P. H., \& Hu, H. (1994). Boron uptake by sunflower, squash and cultured tobacco cells. Physiol Plant, 91, 435-441. https://doi.org/10.1111/j.1399-3054.1994.tb02971.x

Brown, P. H., \& Shelp, B. J. (1997). Boron mobility in plants. Plant soil, 193, 85-101. https://doi.org/10.1023/A:1004211925160

Brown, P. H., Bellaloui, N., Wimmer, M., Bassil, E., Ruiz, J., Hu, H., Romheld, V. (2002).Boron in plant biology. Plant biology, 4(2), 03-223. https://doi.org/ 10.1055/s-2002-25740

Dinca, L., \& Scorei, R. (2013). Boron in human nutrition and its regulations use. J Nutr Ther, 2(1), 22-29. https://doi.org/10.6000/1929-5634.2013.02.01.3

Edwards, J. C., Hunter, J. M., \& Nemzer, B. V. (2014). Multinuclear NMR of calcium fructoborate complex-structure, stability and quantitation in the presence of other ingredients, excipients or adulterants. Journal of Food Research, 3(3), 115-131. https://doi.org/10.5539/jfr.v3n3p115

Hu, H., Penn, S. G., Lebrilla, C. B., \& Brown, P. H. (1997). Isolation and characterization of soluble boron complexes in higher plants. Plant Physiol, 113, 649-655. https://doi.org/10.1104/pp.113.2.649

Kobayashi, M., Matoh, T., \& Azuma, J. I. (1996). Two chains of rhamnogalacturonan II are cross-linked by borate-diol ester bonds in higher plant cell walls. Plant Physiol, 110, 1017-1020. https://doi.org/10.1104/pp.110.3.1017

Makkee, M., Kieboom, A. P. G., \& Bekkum, H. V. (1985). Studies on borate esters III. Borate esters of D-mannitol, D-glucitol, D-Fructose and D-glucose in water, Recl. Trav. Chim. Pays-Bas Belg, 104, 230-235. https://doi.org/ 10.1002/recl.19851040905

Matoh, T., Ishigaki, K. I., Ohno, K., \& Azuma, J. (1993). Isolation and characterization of a boron-polysaccharide complex from radish roots. Plant Cell Physiol, 34(4), 639-642. https://doi.org/10.1093/oxfordjournals.pcp.a078465

Matsunaga, T., \& Nagata, T. (1995). In vivo ${ }^{11}$ B NMR observation of plant tissue. Anal. Sci, 11, 889-892. https://doi.org/10.2116/analsci.11.889

Milijkovic, D., Scorei, R. I., Cimpoiasu, V. M., \& Scorei, I. D. (2009). Calcium fructoborate: plant-based dietary boron for human nutrition. J Diet Suppl, 6(3), 211-226. https://doi.org/10.1080/19390210903070772

Militaru, C., Donoiu, I., Carciun, A., Scorei, I. D., Bulearca, A. M., \& Scorei, R. I. (2013). Oral resveratrol and calcium fructoborate supplementation in subjects with stable angina pectoris: effects on lipid profiles, inflammation markers, and quality of life. Nutrition, 29(1), 178-183. https://doi.org/10.1016/j.nut.2012.07.006

Miljkovic, D. (1999). US patent 5.962 .049 (issued October 5, 1999).

Miljkovic, D., Miljkovic, N., McCarty, M. F. (2004). Up-regulatory impact of boron on vitamin D function -does it reflect inhibition of 24-hydroxylase? Med Hypotheses, 63(6), 1054-6. https://doi.org/10.1016/j.mehy.2003.12.053

Mogosanu, G. D., Bită, A., Bejenaru, L. E., Bejenaru, C., Croitoru, O., Rău, G., Rogoveanu, O. C., Florescu, D. N., Neamtu, J., Scorei, I. D., \& Scorei, R. I. (2016). Calcium fructoborate for bone and cardiovascular health. Biol Trace Elem Res., 172, 277-281. https://doi.org/10.1007/s12011-015-0590-2

Pietrzkowski, Z., Phelan, M. J., Keller, R., Shu, C., Argumedo, R., \& Reyes-Izquierdo, T. (2014) Short-term efficacy of calcium fructoborate on subjects with knee discomfort: a comparative, double-blind, placebo-controlled clinical study. Clinical Interventions in Aging, 9, 895-899. https://doi.org/10.2147/cia.s64590

Reyes-Izquierdo, T., Nemzer, B., Gonzalez, A. E., Zhou, Q., Argumedo, R., Shu, C., \& Pietrzkowski, Zb. (2012). Short-term intake of calcium fructoborate improves WOMAC and McGill Scores and beneficially modulates biomarkers associated with knee osteoarthritis: a pilot clinical double-blinded placebo-controlled 
study. American Journal of Biomedical Sciences, 4(2), 111-122. https://doi.org/10.5099/aj120200111

Scorei, I. D., \& Scorei, R. I. (2013). Calcium fructoborate helps control inflammation associated with diminished bone health. Biol Trace Elem Res., 155(3), 315-321. https://doi.org/10.1007/s12011-013-9800-y

Scorei, R. I. (2011). Calcium Fructoborate: plant-based dietary boron as potential medicine for cancer therapy. Front Biosci (Schol Ed), 3, 205-215. https://doi.org/10.2741/s145

Scorei, R. I., \& Popa, R. (2010). Boron-containing compounds as preventive and chemotherapeutic agents for cancer. Anticancer Agents Med Chem, 10(4), 346-351. https://doi.org/10.2174/187152010791162289

Scorei, R. I., \& Rotaru, P. (2011). Calcium fructoborate-potential anti-inflammatory agent. Biol Trace Elem Res., 143(3), 1223-1238. https://doi.org/10.1007/s12011-011-8972-6

Scorei, R. I., Ciofrangeanu, C., \& Ion, R. (2010). In vitro effects of calcium fructoborate upon production of inflammatory mediators by LPS-stimulated RAW 264.7 macrophages. Biol Trace Elem Res, 135(1-3), 334-344. https://doi.org/10.1007/s12011-009-8488-5

Scorei, R., Cimpoiasu, V. M., \& Iordachescu, D. (2005). In vitro evaluation of the antioxidant activity of calcium fructoborate. Biol Trace Elem Res., 107(2), 127-34. https://doi.org/10.1385/BTER:107:2:127

Scorei, R., Ciubar, R., Ciofrangeanu, C. M., Mitran, V., Cimpean, A., \& Iordachescu, D. (2007). Comparative effects of boric acid and calcium fructoborate on breast cancer cells. Biol Trace Elem Res., 118(1), 27-37. https://doi.org/10.1007/s12011-007-0019-7

Scorei, R., Mitrut, P., Petrisor, I., \& Scorei, I. (2011). A double-blind, placebo-controlled pilot study to evaluate the effect of calcium fructoborate on systemic inflammation and dyslipidemia markers for middle-aged people with primary osteoarthritis. Biol Trace Elem Re., 144(1-3), 253-263. https://doi.org/10.1007/s12011-011-9083-0

Wagner, C. C., Ferraresi, Curotto, V., Pis, Diez, R., \& Baran, E. J. (2008). Experimental and theoretical studies of calcium fruotoborate. Biol Trace Elem Res., 122(1), 64-72. https://doi.org/10.1007/s12011-007-8060-0

\section{Copyrights}

Copyright for this article is retained by the author(s), with first publication rights granted to the journal.

This is an open-access article distributed under the terms and conditions of the Creative Commons Attribution license (http://creativecommons.org/licenses/by/4.0/). 